\title{
How to Build Guanxi Quality: An Empirical Investigation in China
}

\author{
Jia Shen \\ School of Management \\ Jilin University \\ Changchun, Jilin Province, China \\ Shenjia0308@126.com
}

Abstract-China is a guanxi-oriented nation. Compared to the Western relational marketing concept, Guanxi incorporates the notion of ganqing and renqing. Based on its unique cultural and institutional backgrounds, Chinese guanxi is a mixture of the affect and instrumentality. This article posits and examines a measurement scale for measuring guanxi quality based on Chinese guanxi constructs-renqing, ganqing, xinren, and western relational structure-satisfaction, commitment. The results develop a multi-dimensional measure in this study, offering a useful starting point in order for business practitioners to assess their guanxi and at the same time provide academics with a scale for operationalizing the measurement of guanxi quality.

Keywords-guanxi quality; scale development; Chinese culture; Market quanxi; Government quanxi

\section{INTRODUCTION}

Guanxi as a cultural construct is ubiquitous in all Confucian societies and has been proved valuable when doing business within institutional and economic contexts[1][2]. The guanxi research covered here clearly refers to human relationships. With the development of China's economy, more and more scholars use the social networking theory to explain the unique management phenomenon in China. Guanxi network in China is a set of knowledge hierarchy embedded with renqing(favor), mianzi (face), xinren(trust), responsibility and obligation. Therefore, in the special Chinese cultural backgrounds, the factors affecting enterprise performance are not merely such factor as guanxi intensity; destiny and range often used in the western social networking, but focus more on the guanxi quality with emotional features of traditional Chinese culture.

The relevant research on guanxi quality can be traced back to the description of buyer-seller relations according to[3]. Now it is widely accepted in the theoretical circle that guanxi quality is put forward and clearly defined by[5], used to describe the level of trust and satisfaction between each other. Soon afterwards, numerous scholars have researched a lot on guanxi quality. The use of mature scale developed by the westerners in measuring guanxi quality between enterprises and government is short of scientificness and effectiveness and will affect the entrepreneurship study in guiding the practice. This paper is aiming to preliminarily explore the deficiencies in the above theory, develop Chinese guanxi quality scale of government-market relations with both expressive and instrumental characteristics. expectations.

\author{
Xueling Lee \\ School of Management \\ Jilin University \\ Changchun, Jilin Province, China
}

II. THEORETICAL BACKGROUND

\section{A. Guanxi Quality}

The study of guanxi quality first appeared in the field of marketing, reflecting the interaction quality between enterprises and customers, an important component in perceiving quality of enterprises' service by customers. Now it is universally accepted in the academic circles that guanxi quality refers to the acknowledgement and evaluation of intimacy degree on mutual relations by the subject of guanxi. On the basis of summarizing the previous research, this paper believes that guanxi quality refers to the acknowledgement and evaluation by the subject of guanxi according to certain standards and principles of social norms on whether the long-term relations establishment, mutual trust and loyalty, responsibility maintenance of both sides (individual or organization) have reached the mutual

\section{B. Guanxi characteristics}

In the process of China's economic reform and market development, social relations accordingly have stamped marks of time. China's reform of economic system is a transition from planned economy to market economy. We still keep the intervention by the strong government in the planned economy period. With the continuous development of market economy, the government-market dual structure takes shape in China[4]. They share key resources and information which enterprises need and dominate the business activities of enterprises, which bring about the political-commercial relations and commercialcommercial relations in Chinese guanxi network, different from the western mature economy. The business activities of enterprises not only depend on the contractual activities of the market. The exchange of some asymmetric market information is built on the basis of renqing and feelings. Such non-systematic cultural factors as blood relationship and kinship still play an irreplaceable and unique role in mutual communication and getting consensus. In consequence, enterprises need to build both government relations and market relations of highqualities to solve the problems of scarce resources and asymmetric information, help enterprises to cope with the uncertainty, hostilities and complexities in the institutional environment and improve the capability of bearing risks. Due to the special economic status with both market and government in the transition period and the silent transforming and sustainable influ- 
ence of traditional culture, Chinese guanxi network is a mixed type of network with emotional and institutional characteristics. Market and enterprises are main targets in establishing relations for enterprises.

\section{METHOD}

\section{A. Procedure}

In this paper, we adopt the procedure of scale development as presented follows. The preliminary measurement items are formed on the basis of literature review and start-up interview. After the confirmation and revision, the preliminary measurement scale takes shape. Then we conduct two rounds of pre- survey and formal survey, and use questionnaire to measure relevant variables involved in the mode. Likert-7 scale is used in the questionnaire. We did exploratory factor analysis (EFA) and confirmatory factor analysis (CFA) on the data collected in the pre-survey and formal survey and ruled out invalid and unqualified items which guaranteed the content validity and structure validity of the scale. To insure the quality of developed scale, we did supplementary survey and compared the existing mature scale with the one in this paper. Finally, we developed guanxi quality scale with Chinese cultural and transitional characteristics.

TABLE I. SAMPLES

\begin{tabular}{ccccc}
\hline Questionnaire Status & Sent to & $\begin{array}{c}\text { Sending-out } \\
\text { numbers }\end{array}$ & $\begin{array}{c}\text { Taking-back } \\
\text { numbers }\end{array}$ & Effective Questionnaire \\
\hline 1st round survey & MBA students & 100 & $63(63 \%)$ & $52(52 \%)$ \\
\hline 2nd round survey & $\begin{array}{c}\text { Senior officers of enterpris- } \\
\text { es }\end{array}$ & 50 & $28(56 \%)$ & $164(55 \%)$ \\
\hline Formal survey & Entrepreneurs & 300 & $168(67 \%)$ & $127(42 \%)$ \\
\hline Supplementary survey A & $\begin{array}{c}\text { Entrepreneurs \& Employ- } \\
\text { ees }\end{array}$ & $250 \%)$ & $156(62 \%)$ & $126(50 \%)$ \\
\hline Supplementary survey B & $\begin{array}{c}\text { Entrepreneurs \& Employ- } \\
\text { ees }\end{array}$ & 250 & $581(61 \%)$ & $451(47 \%)$ \\
\hline
\end{tabular}

\section{B. Factor Analysis}

We used Kaiser-Meyer-Olkin measure and Bartlett measure to test the samples, and results show that the original data are suitable for doing factor analysis. Five dimensions are extracted for market relations - renqing, feeling, trust, commitment, and satisfaction. Four dimensions are extracted for government relations - renqing, feeling, trust and commitment. We then revised some items and confirmed the questionnaire for the 2nd round pre-survey. In this version of questionnaire, there are 42 items on market guanxi quality, and 49 on government guanxi quality.

By summing up the analysis results of two rounds of presurvey, we confirmed the questionnaire for formal survey and did CFA on the collected data. The lowest coefficient of Cronbachs Alpha for items of market guanxi quality is 0.765 .

The lowest variance contributing rate is $52.398 \%$; the lowest coefficient of Cronbach's Alpha for items of government guan$\boldsymbol{x i}$ quality is 0.81 , and the lowest variance contributing rate is $52.06 \%$.

\section{Reliability and Validity}

The test is aiming to verify the reliability of the scale, the higher coefficient we get, it means the more consistency the test content is. We analyzed current relative literature, consulted to a large number of guanxi quality scale, interviewed entrepreneurs, and asked several experts to evaluate and revise the scale. We tried all the best to list as many items in guanxi quality scale as possible to make the scale of more content validity. The analysis result shows that the scale has good structure validity. 
TABLE II. FACTOR ANALYSIS OF MARKET GUANXI QUALITY

\begin{tabular}{|c|c|c|c|c|c|c|c|c|}
\hline $\begin{array}{c}\text { Market guanxi } \\
\text { quality }\end{array}$ & $\begin{array}{l}\text { Variable indi- } \\
\text { cator }\end{array}$ & Factor1 & Factor 2 & Factor 3 & Factor 4 & Factor 5 & $\begin{array}{c}\text { Cronbach's } \\
\text { Alpha }\end{array}$ & $\begin{array}{c}\text { Variance contrib- } \\
\text { uting rate }\end{array}$ \\
\hline \multirow[t]{3}{*}{ Renqing } & $\mathrm{V} 1$ & 0.894 & & & & & 0.87 & $79.77 \%$ \\
\hline & V3 & 0.862 & & & & & & \\
\hline & $\mathrm{V} 2$ & 0.837 & & & & & & \\
\hline \multirow[t]{4}{*}{ Ganqing } & V5 & & 0.852 & & & & 0.83 & $66.98 \%$ \\
\hline & V6 & & 0.779 & & & & & \\
\hline & V4 & & 0.702 & & & & & \\
\hline & V7 & & 0.595 & & & & & \\
\hline \multirow[t]{3}{*}{ Trust } & V8 & & & 0.769 & & & 0.80 & $71.93 \%$ \\
\hline & V9 & & & 0.763 & & & & \\
\hline & V10 & & & 0.761 & & & & \\
\hline \multirow[t]{4}{*}{ Satisfaction } & V14 & & & & 0.8 & & 0.88 & $74.57 \%$ \\
\hline & V13 & & & & 0.717 & & & \\
\hline & V12 & & & & 0.686 & & & \\
\hline & V11 & & & & 0.684 & & & \\
\hline \multirow[t]{3}{*}{ Commitment } & V17 & & & & & 0.811 & 0.76 & $67.57 \%$ \\
\hline & V16 & & & & & 0.797 & & \\
\hline & V15 & & & & & 0.652 & & \\
\hline
\end{tabular}

TABLE III. FACTOR ANALYSIS OF GOVERNMENT GUANXI QUALITY

\begin{tabular}{|c|c|c|c|c|c|c|c|}
\hline $\begin{array}{c}\text { Government guanxi } \\
\text { quality }\end{array}$ & $\begin{array}{l}\text { Variable indica- } \\
\text { tor }\end{array}$ & Factor1 & Factor 2 & Factor 3 & Factor 4 & $\begin{array}{l}\text { Cronbach's } \\
\text { Alpha }\end{array}$ & $\begin{array}{c}\text { Variance contrib- } \\
\text { uting rate }\end{array}$ \\
\hline \multirow[t]{4}{*}{ Renqing } & V2 & 0.941 & & & & 0.95 & $87.42 \%$ \\
\hline & V3 & 0.918 & & & & & \\
\hline & V1 & 0.897 & & & & & \\
\hline & V4 & 0.883 & & & & & \\
\hline \multirow[t]{3}{*}{ Ganqing } & V9 & & 0.798 & & & 0.86 & $77.70 \%$ \\
\hline & V10 & & 0.568 & & & & \\
\hline & V15 & & 0.493 & & & & \\
\hline \multirow[t]{4}{*}{ Trust } & V14 & & & 0.891 & & 0.95 & $87.24 \%$ \\
\hline & V13 & & & 0.859 & & & \\
\hline & V12 & & & 0.840 & & & \\
\hline & V11 & & & 0.826 & & & \\
\hline \multirow[t]{4}{*}{ Commitment } & V6 & & & & 0.733 & 0.92 & $80.97 \%$ \\
\hline & V7 & & & & 0.731 & & \\
\hline & V8 & & & & 0.714 & & \\
\hline & V5 & & & & 0.710 & & \\
\hline
\end{tabular}

\section{CONCLUSIOnS}

\section{A. Theoretical implications}

On the basis of Chinese traditional culture and special institution environment in transition economy, we developed market guanxi quality scale with five dimensions - renqing, feelings, trust, commitment and satisfaction, and government guanxi quality scale with four dimensions - renqing, feeling, trust and commitment. The two scales have different dimensions, and corresponding item contents are also different. The scale development results demonstrate the important role that emotional characteristics of Chinese guanxi quality and traditional culture play. It also further verifies uniqueness of the coexistence of government and market network in the transition context [4] and the necessity of dividing guanxi quality into government guanxi quality and market guanxi quality. 


\section{B. Managerial implications}

We develop a guanxi quality scale in this paper which is suited to the study of business set-up in China. It verifies the unique dimensions of market guanxi quality and government guanxi quality influenced by Chinese traditional culture and transition economy, reveals different connotations and construction manners of government guanxi quality and market guanxi quality, and their distinctive roles in the development of enterprises. It also demonstrates the unique impact of Chinese context to business set-up and lays a solid theoretical foundation for the study of social network of Chinese newly built enterprises. In addition, this paper enriches the study of businessstarting field and has theoretical value in digging the connotations of Chinese context and its influence in other fields. The scale and its conclusions are favorable to guiding the entrepreneurs to build reasonable government relations and market relations so as to remedy the defect of inadequate resources, poor opportunity identification ability and low legality, and improve its survival ability[6]. Furthermore, government policy makers can get some enlightenment from the conclusions in the paper and consider how to create a favorable economic environment for newly set-up enterprises and policy environment for the cooperation and communication among entrepreneurs.

\section{ACKNOWLEDGMENT}

This research was supported by the National Natural Science Foundation of China (NSFC) under grants No.71472072 and 71232011.

\section{REFERENCES}

[1] Chen, C. C., Chen, X. P., \& Huang, S.(2013). Chinese Guanxi: An Integrative Review and New Directions for Future Research. Management and Organization Review, 9(1), 167-207

[2] Granovetter M., (1973).The strength of weak ties. A merican journal of sociology, 1360-1380.

[3] Levitt, T. (1986). Marketing Imagination: New. Simon and Schuster.

[4] Peng M. W., Luo Y., (2000). Managerial ties and firm performance in a transition economy: The nature of a micro-macro link. Academy of management journal, 43(3),486-501.

[5] Crosby L. A., Evans K. R., Cowles D.(1990). Relationship quality in services selling: an interpersonal influence perspective. The journal of marketing, 54(3),68-81.

[6] Luo, Y., Huang, Y., \& Wang, S. L. (2012). Guanxi and organizational performance: A meta-analysis. Management and Organization Review, 8(1),139-172 